\title{
Ultrasonographic Prediction of Hepatic Fat Content in Dairy Cows during the Transition Period
}

\author{
Mohamed Tharwat ${ }^{1}$, Shin Oikawa ${ }^{2}$ and Sébastien Buczinski ${ }^{3 *}$
}

${ }^{1}$ Department of Veterinary Medicine, College of Agriculture and Veterinary Medicine, Qassim University, Saudi Arabia

${ }^{2}$ Department of Veterinary Herd Health, School of Veterinary Medicine, Rakuno Gakuen University, 582 Bunkyodai-Midorimachi, Ebetsu, Hokkaido 069-8501, Japan

${ }^{3}$ Bovine Ambulatory Clinic, Department des Sciences Cliniques, Faculté de Médecine Vétérinaire, Université de Montréal, Saint-Hyacinthe, Canada

\begin{abstract}
The objective of the present study was to emphasize the value of ultrasonography in predicting hepatic fat content in dairy cows during the transition period. For this purpose, five dairy cows during the transition period were examined by ultrasonography 3 times during this phase, $3 w k$ before expected partition (wk -3 ), at parturition (wk 0 ) and $3 w k$ after parturition $(w k+3)$. Parallel, blood samples were collected and livers were biopsied. None of the cows showed clinical disease around calving. Compared with precalving values, the hepatic triglyceride and glycogen concentrations were higher at parturition (wk 0$)$ and thereafter (wk +3$)$. Histopathologically, there were no cellular abnormalities in hepatocytes 3 weeks before parturition. However, at parturition the hepatocytes contained some lipid drops in cytosol, and the cells after parturition $(w k+3)$ turn opacificated severely and cellular membranes are indistinct. With increased liver TG content, hepatic ultrasonography showed increased overall echogenicity with vascular blurring. In the field, the visual evaluation of the brightness of hepatic tissue in dairy cows during the transition period can give a rough, but quick estimate of the liver fat content. To the best of the authors' knowledge, this study is the first that shows hepatic changes by ultrasonography in dairy cows during the transition period.
\end{abstract}

Keywords: Cow; Liver; Transition period; Triglyceride; Ultrasonography

\section{Introduction}

The importance of the transition period in dairy cows has been highlighted in several review articles [1-3]. This period, $3 \mathrm{wk}$ before to 3 wk after parturition, is characterized by marked changes in the endocrine status of the animal that are much more dramatic than at any other time in the lactation-gestation cycle, and a reduction in feed intake when nutrient demand for the developing conceptus and the impending lactogenesis are increasing [4].

During transition phase the cow has to adapt to a dramatic and several-fold increase in nutrient uptake by the mammary gland associated with lactogenesis compared with the much smaller nutrient requirement in late gestation by the growing conceptus. The period is thus associated with an increased incidence of metabolic and production-related diseases, including fatty liver and ketosis, arising because of inadequate homeorhetic adaptation of metabolism $[2,5,6]$. These conditions, together with changes in hormonal equilibrium, lead to an increase in fat mobilization with consequent increased plasma non-esterified fatty acids (NEFA) and rate of fatty acids uptake from the liver [1]. When the rate of hepatic triglycerides (TG) synthesis exceeds the rate of TG disappearance, accumulation of TG and cholesterol esters in hepatocytes takes place with a higher risk for fatty liver. Triglycerides may disappear through hydrolysis or secretion via very low-density lipoproteins (VLDL) synthesis [7]. Ruminants have the same rate of TG synthesis in the liver compared with nonruminants but have a very slow rate of hepatic VLDL secretion relative to nonruminants [8].

The accurate assessment of hepatic fat content has been restricted up until now to biochemical or histological examination of liver biopsy specimens $[9,10]$. For on-farm testing, liver biopsies are impractical because of the time needed for acquiring and analyzing them [11], temporary discomfort to cows, potential risk of infection, and can rarely be lethal if a major blood vessel is punctured [12]; therefore, a non-invasive technique would be very useful.
In humans, ultrasonography has been shown to be more accurate than biochemical analysis in the diagnosis of fatty infiltration of the liver [13]. In cows, ultrasound imaging has been used for detection of liver diseases [14]. Detection of fatty liver is more difficult because it results in smaller changes of hepatic echo-structure [14]. Textural characteristics of fatty liver ultrasonograms include fine echogenicity, vascular blurring, acoustic backscatter and hypoechoic areas $[15,16]$. Fatty liver is detected also through a non-invasive technique of digital analysis of hepatic ultrasonograms [11,16-18]. Although more accurate, the procedure is time consuming and needs much experience as well as sophisticated software that are not easily available for the bovine practitioner. Therefore, we undertook this study to investigate the utility of a quick method of hepatic ultrasonography in dairy cows during the transition period for rapid field prediction the degree of hepatic fat content.

\section{Materials and Methods}

\section{Animals}

Five pregnant Holstein cows ( $2.5 \pm 0.59$ years old), weighed $562-758$ $\mathrm{kg}(657 \pm 90)$ were used in this study. Their parities ranged from 1 to 3 (1.6 \pm 0.89$)$. On a scale from 1 to 5 ( $1=$ thin, $5=$ =bese; [19], their body condition score ranged from 3.25 to 3.75 ( $3.5 \pm 0.21)$. Three of the cows had a decreased appetite. All animals underwent a thorough physical

*Corresponding author: Dr. Sébastien Buczinski, Bovine Ambulatory Clinic, Department des Sciences Cliniques, Faculté de Médecine Vétérinaire, Université de Montréal, Saint-Hyacinthe, Canada, E-mail: s.buczinski@umontreal.ca

Received February 22, 2011; Accepted October 28, 2011; Published January 04, 2011

Citation: Tharwat M, Oikawa S, Buczinski S (2012) Ultrasonographic Prediction of Hepatic Fat Content in Dairy Cows during the Transition Period. J Veterinar Sci Technol 3:111. doi:10.4172/2157-7579.1000111

Copyright: (c) 2012 Tharwat M, et al. This is an open-access article distributed under the terms of the Creative Commons Attribution License, which permits unrestricted use, distribution, and reproduction in any medium, provided the original author and source are credited. 
examination [20], which included general behavior and condition, auscultation of the heart, lungs, rumen and intestine, measurement of heart rate, respiratory rate and rectal temperature, swinging auscultation, percussion auscultation of both sides of the abdomen and rectal examination. All cows were maintained in tie-stall barns under the Laboratory Animal Control Guidelines of Rakuno Gakuen University, Japan, which basically conform to the Guide for the Care and Use of Laboratory Animals of the National Institutes of Health in the USA (NIH publication No. 86-23, revised 1996).

\section{Hematological and biochemical analyses}

Blood samples were withdrawn and liver biopsies were carried out 3 weeks before ( $21.4 \pm 4.6$ days), $24 \mathrm{hr}$ after parturition and 3 weeks after parturition. Two blood samples were collected by puncture of the jugular vein, one on EDTA and the other without anticoagulant. A complete blood count (hematocrit, hemoglobin, erythrocyte and leucocyte count) was carried out on the first blood sample. After centrifugation of the second blood sample, serum samples were collected and then frozen for later analysis of clinical chemistries. In the serum, commercial kits were used to determine the concentrations of total protein, albumin, calcium, phosphorus, glucose, total cholesterol and non-esterified fatty acids (NEFA). The activities of aspartate aminotransferase (AST) were also measured in serum samples. Serum protein fractions were determined by electrophoresis.

\section{Hepatic ultrasonography}

Liver ultrasonograms were acquired with a real-time ultrasound machines (SSD-500, Aloka, Tokyo, Japan) equipped with $3.5 \mathrm{MHz}$ sector transducers. The area between the $5^{\text {th }}$ to $12^{\text {th }}$ ribs was clipped and shaved. The transducer was placed parallel to the ribs and between the dorsal and middle third of the $12,11,10,9,8,7,6$ and $5^{\text {th }}$ intercostal spaces. Ultrasonographic settings (NG-2, FG 3.2, BG 3, DYN 3, ENH $2 / 2$, and SCC 1 ) were kept the same for all ultrasound images. The liver was examined caudocranially and dorsoventrally $[21,22]$. Ultrasonic coupling gel was liberally applied to the wet skin to ensure good contact. With the exception of mild hepatic lipidosis, none of the cows used in this study suffered from any hepatic disorders.

\section{Liver biopsy}

Under ultrasound guidance, liver biopsy was carried out as previously described [21-23]. Briefly the procedure is as follows: the areas over the intercostal spaces 7 to 12 on the right side were surgically prepared. All animals were evaluated ultrasonographically for haemorrhage immediately prior to the procedure [24,25]. Biopsy site was then infiltrated with $5 \mathrm{ml}$ of $2 \%$ procaine hydrochloride. Prior to biopsy, a small incision was made immediately adjacent to the transducer through the skin and abdominal wall with the point of a scalpel blade. With a free-hand technique, a $14 \mathrm{G} \times 150 \mathrm{~mm}$ spinal biopsy needle (Kurita Co., Ltd, Tokyo, Japan) was advanced through the hepatic parenchyma under direct ultrasound control. When the needle was considered to be in the correct position, the plain stylet was withdrawn and a notched part inserted and advanced. Often the needle can be identified on ultrasound within the hepatic parenchyma while the specimen is being obtained, thus confirming the location of biopsy. Liver specimens were fixed in neutral buffered $10 \%$ formalin and processed routinely for staining with hematoxylin and eosin (H\&E). Liver TG and glycogen content were determined in hepatic tissue as described previously $[21,22]$. The hepatic TG content was used as the "gold standard" for fatty infiltration of liver tissue. The hepatic TG content was expressed as $\mathrm{mg} / \mathrm{g}$ liver fresh weight and used as reference value for fatty liver.

\section{Statistical analysis}

Data are presented as mean \pm SD and the analysis was conducted using SPSS program, version 16.0 [26]. Hematological and biochemical data $3 \mathrm{wk}$ before, at parturition and $3 \mathrm{wk}$ after parturition were compared, using repeated measures of ANOVAS. The level of significance was set at $P<0.05$.

\section{Results}

None of the 5 cows showed clinical disease around calving. Compared to values at $3 \mathrm{wk}$ before parturition $(657 \pm 90 \mathrm{~kg})$, body weight in all cows decreased dramatically at parturition $(604 \pm 73 \mathrm{~kg})(P<0.05)$ and at $3 \mathrm{wk}$ postcalving $(556 \pm 68 \mathrm{~kg})(P<0.01)$. The BCS decreased significantly $3 \mathrm{wk}$ after parturition where it reduced to $2.9 \pm 0.14(P<$ $0.05)$ compared to values of $3.5 \pm 0.21$ at 3 wk precalving.

Table 1 summarizes the hematological and biochemical findings and liver TG and glycogen in the 5 examined cows. Complete blood count data did not differ significantly among the three examined periods. The activities of AST were significantly higher at parturition (191 $\pm 175 \mathrm{U} / \mathrm{L}$ vs. $79 \pm 23 \mathrm{U} / \mathrm{L} 3 \mathrm{wk}$ before parturition). The concentrations of NEFA were significantly increased $(P<0.01)$ during all periods of examination. The concentrations of BHBA were also high at parturition and at $3 \mathrm{wk}$ after parturition. Other serum parameters including total protein and its fractions, calcium, phosphorus, glucose and total cholesterol did not differ among the 3 examined periods of the transition phase. On average, the TG concentration was highest $(P<0.01)$ at parturition $(138 \pm 89 \mathrm{mg} / \mathrm{g}$ wet tissue) (wk0) and after partition $(115 \pm 58 \mathrm{mg} / \mathrm{g}$ wet tissue) $(\mathrm{wk}+3)$ compared with precalving values $(47 \pm 11 \mathrm{mg} / \mathrm{g}$ wet tissue) (wk-3). Similarly, the glycogen concentration was highest $(P$ $<0.01)$ at parturition $(336 \pm 139 \mathrm{mg} / \mathrm{g}$ wet tissue) $(P<0.01)($ wk0) and after parturition $(281 \pm 49)(P<0.05)(w \mathrm{k}+3)$ compared with precalving values $(176 \pm 74 \mathrm{mg} / \mathrm{g}$ wet tissue) (wk-3).

Figure 1 shows hepatic ultrasonograms in 3 cows during the transition period. With increased liver TG content, hepatic

\begin{tabular}{|c|c|c|c|}
\hline Parameters & $-3 W$ & $0 \mathrm{w}$ & $+3 w$ \\
\hline Temperature $\left({ }^{\circ} \mathrm{C}\right)$ & $38.7 \pm 0.3$ & $38.8 \pm 0.5$ & $39.1 \pm 0.6$ \\
\hline Pulse (/min) & $81 \pm 7$ & $100 \pm 13$ & $87 \pm 4$ \\
\hline Respiration (/min) & $28 \pm 10$ & $23 \pm 5$ & $21 \pm 2$ \\
\hline Hematocrit (\%) & $34 \pm 0.5$ & $37 \pm 3$ & $33 \pm 3$ \\
\hline Hemoglobin (g/dL) & $13.4 \pm 0.41$ & $14.5 \pm 0.68$ & $12.8 \pm 1.68$ \\
\hline Erythrocytes $\left(\times 10^{4} / \mu \mathrm{L}\right)$ & $895 \pm 72$ & $970 \pm 34$ & $878 \pm 140$ \\
\hline Leukocyte count $(/ \mu \mathrm{L})$ & $102 \pm 16$ & $112 \pm 31$ & $96 \pm 11$ \\
\hline Total protein $(\mathrm{g} / \mathrm{dL})$ & $6.1 \pm 0.69$ & $6.4 \pm 0.48$ & $7.2 \pm 0.99$ \\
\hline Albumin (g/dL) & $3.4 \pm 0.5$ & $3.4 \pm 0.3$ & $3.4 \pm 0.4$ \\
\hline a-globulin (g/dL) & $0.78 \pm 0.15$ & $0.98 \pm 0.42$ & $1.25 \pm 0.57$ \\
\hline$\beta$-globulin (g/dL) & $0.86 \pm 0.37$ & $0.85 \pm 0.35$ & $0.99 \pm 0.21$ \\
\hline Y-globulin (g/dL) & $1.3 \pm 0.1 .34$ & $1.23 \pm 1.07$ & $1.88 \pm 1.31$ \\
\hline Aspartate aminotransferase (U/L) & $79 \pm 23$ & $191 \pm 175^{*}$ & $98 \pm 45$ \\
\hline Calcium (mg/dL) & $11 \pm 1.1$ & $10 \pm 0.9$ & $10 \pm 0.6$ \\
\hline Phosphorus (mg/dL) & $6.9 \pm 0.8$ & $5.2 \pm 2.1$ & $4.9 \pm 1.4$ \\
\hline Glucose $(\mathrm{mg} / \mathrm{dL})$ & $69 \pm 6$ & $68 \pm 7$ & $68 \pm 11$ \\
\hline Free fatty acids (mEq/L) & $0.52 \pm 0.26^{* *}$ & $0.69 \pm 0.23^{* *}$ & $0.59 \pm 0.09^{* \star}$ \\
\hline Total cholesterol (mg/dL) & $84 \pm 39$ & $62 \pm 34$ & $165 \pm 17$ \\
\hline Triglycerides (mg/dL) & $17 \pm 8$ & $8 \pm 2$ & $8 \pm 2$ \\
\hline Liver triglyceride (mg/g wet tissue) & $47 \pm 11$ & $138 \pm 89^{* *}$ & $115 \pm 58^{* *}$ \\
\hline Liver glycogen (mg/g wet tissue) & $176 \pm 74$ & $336 \pm 139^{* *}$ & $281 \pm 49^{* *}$ \\
\hline
\end{tabular}

Data are expressed as mean $\pm \mathrm{SD}$. ${ }^{*} P<0.0 .5 ;{ }^{* *} P<0.0 .1$

Table 1: Serial clinical and laboratory findings in 5 cows $3 w k$ before $(-3 w)$, at parturition $(0 w)$ and $3 w k$ after parturition $(+3 w)$. 
Citation: Tharwat M, Oikawa S, Buczinski S (2012) Ultrasonographic Prediction of Hepatic Fat Content in Dairy Cows during the Transition Period. J Veterinar Sci Technol 3:111. doi:10.4172/2157-7579.1000111

Page 3 of 5

ultrasonography showed beam attenuation and backscattering, fine echogenicity and vascular blurring increased, of which beam attenuation was the most prominent change at higher TG infiltration. Figure 2 shows microscopic images of liver cells during the transition period. No cellular abnormalities were found in any of hepatocytes at 3 wk before parturition. However, the hepatocytes at parturition (wk 0 ) contained some lipid drops in cytosol, and the cells after at $3 \mathrm{wk}$ after parturition turn opacificated severely and cellular membranes are indistinct.

\section{Discussion}

Changes of BCS, glucose, NEFA, BHBA, cholesterol, calcium, phosphorus, albumin and other serum parameters around parturition observed in the present study can be considered physiological and due to the negative energy balance and changes in the activity of liver which are generally observed during the transition period in dairy cows $[9,27]$. It should be emphasized that cows in our study developed mild fatty liver. According to Jorritsma et al. [28], the majority of cows in commercial dairy herds develop mild fatty livers. It seems that mildly

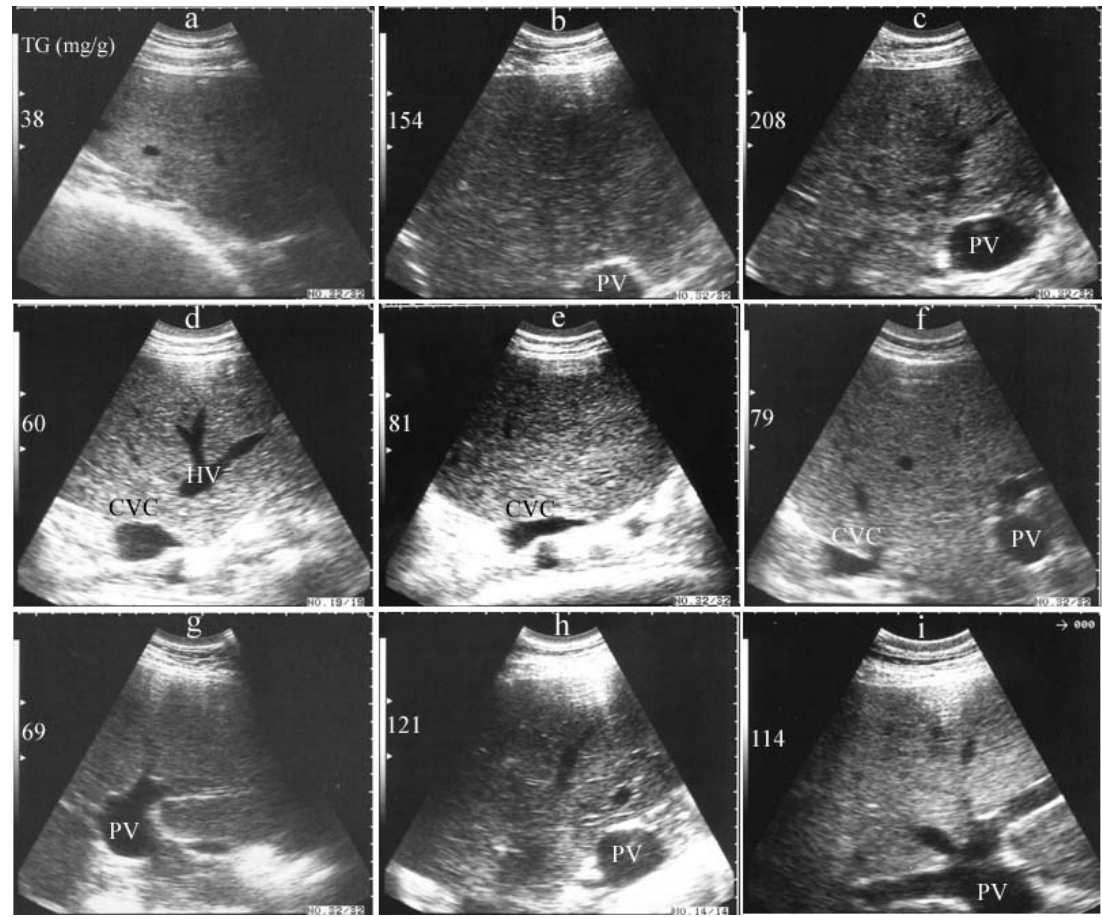

Figure 1: Hepatic ultrasonograms in 3 cows during the transition period. Images were taken $3 w k$ before expected parturition (a, d, g), at parturition (b, e, h) and 3wk after parturition (c, f, i). With increased liver triglyceride (TG) content in cow 1 (a, b, c), hepatic ultrasonography showed a gradual increased echogenicity with vascular blurring. In cow 2 (d, e, f), with increased hepatic TG content hepatic echogenicity increased at parturition and then declined $3 w k$ after parturition parallel to TG content. In cow 3 (g, h, i), hepatic echogenicity increased also with increased hepatic TG content.

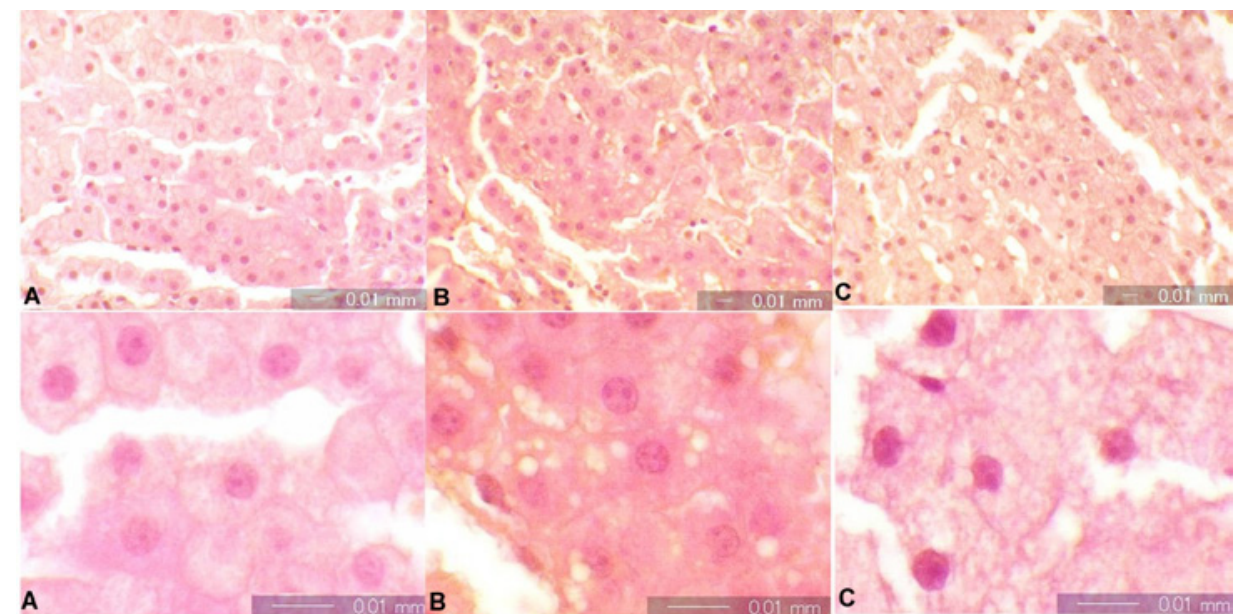

Figure 2: Histopathology and immunohistochemistry of the liver during the transition period. No cellular abnormalities were found in any of hepatocytes 3 weeks before parturition (A). However, the hepatocytes at parturition (wk 0) (B) contain some lipid drops in cytosol, and the cells after 3 weeks parturition (C) turn opacificated severely and cellular membranes are indistinct (HE staining). 
elevated BHBA concentrations observed in the present study and in another study [10] are similar to those occurring in cows with mild fatty liver during the transition period. Peak liver TG accumulation occurred at parturition (wk 0$)$ and postcalving (wk -3$)(P<0.01)$, which agrees with other report that suggest peak of hepatic TG accumulation within the first 2 wk of lactation [29]. These findings were confirmed by histological examination of hepatic specimens where, on the contrary of prepartum data ( $\mathrm{wk}-3)$, numerous fat vacuoles were detected within the hepatocytes at parturition (wk 0$)$ and thereafter $(w \mathrm{k}+3)$.

During early lactation, a negative energy balance causes enhance lipid mobilization and an accompanying increased fat storage in the liver by way of a hepatic TG increase $[1,4]$. This conformed to our results in Table 1 showing considerable fat accumulation in hepatic tissue to be almost exclusively seen in cows at parturition and $3 \mathrm{wk}$ after. It is not known exactly why liver TG and glycogen and NEFA values are high in our cows compared to that reported previously in clinical healthy Holstein cows. Inappetance recorded in 3 of the cows may be a contributing factor. Because it was reported that accumulated fat in the liver is homogenously distributed over the entire organ [11], it appears to be justified to take the TG content of small hepatic biopsies as representative of the whole liver and therefore as a gold standard.

Although biochemical analysis and analysis of biopsy specimens have been extensively used in the diagnosis of hepatic fat contents, the former has the disadvantage of being relatively unreliable with the latter is considered too invasive for routine use. The very low predictive value for biochemical analysis in this study showed that this method cannot be used for predicting high levels of hepatic fat. The use of ultrasonography on the other hand, can show actual hepatic changes since real-time images of liver can be obtained. Because of the high echogenicity of fat, the presence of fat infiltration can be demonstrated by ultrasonography [30]. The high echogenicity of fat is due to its lower acoustic impedance in contrast with that of the normal liver tissue [31].

The normal echo pattern of the liver is caused mainly by a series of alternate collagen-water interfaces. In this study, the hepatic brightness increased with higher hepatic TG contents. With hepatic fat accumulation the liver appears more echogenic and brighter on the ultrasound screen. With increasing fat accumulation in hepatic tissue, an increased gray level in the ultrasound image is seen and the liver appears subjectively brighter $[11,14,32]$. However, the gray level of US images is dependent not only on tissue structure but also on the actual characteristics and settings of the ultrasound scanner. For this reason, the equipment settings as well as the examination technique need to be standardized. Moreover, visual inspection of the ultrasound images by the examiner introduces a subjective factor into the assessment of image gray level. Thus, the visual evaluation of the brightness of hepatic tissue in ultrasound images can give a rough but quick estimate of the liver fat content. With increased liver TG content, beam attenuation and backscattering, fine echogenicity and vascular blurring increased, of which beam attenuation was the most prominent change at higher TG infiltration. Such characteristics are typical for increased hepatic fat content in dairy cattle and other species $[15,16]$.

The visual evaluation of the brightness of hepatic tissue in US images can give only a rough, but quick estimate of the liver fat content. Furthermore, the high inter- and intraobserver variability inherent in subjective methods prohibits a high level of reliability of the results [33]. Hepatic ultrasonography during the transition period could provide important technology for rapid non-invasive, on-farm diagnosis and thereby more effective treatment of fatty liver in dairy cows. Ultrasonography is therefore recommended instead of biochemical analysis and histological examination of hepatic biopsy specimens in predicting hepatic fat contents in dairy cows.

\section{References}

1. Grummer RR (1995) Impact of changes in organic nutrient metabolism on feeding the transition dairy cow. J Anim Sci 73: 2820-2833.

2. Ingvartsen KL, Dewhurst RJ, Friggens NC (2003) On the relationship between lactational performance and health: is it yield or metabolic imbalance that cause production diseases in dairy cattle? A position paper. Livestock Production Science 83: 277-308.

3. Mulligan FJ, Doherty ML (2008) Production diseases of the transition cow. Vet J 176: 3-9.

4. Drackley JK (1999) ADSA Foundation Scholar Award. Biology of dairy cows during the transition period: The final frontier? J Dairy Sci 82: 2259-2273.

5. Ingvartsen KL, Andersen JB (2000) Integration of metabolism and intake regulation: a review focusing on periparturient animals. J Dairy Sci 83:15731597.

6. Friggens NC, Andersen JB, Larsen T, Aaes O, Dewhurst RJ (2004) Priming the dairy cow for lactation: A review of dry cow feeding strategies. Anim Res 53 : 453-473.

7. Oikawa S, Mizunuma Y, Iwasaki Y, Mohamed T (2010) Changes of very low-density lipoprotein concentration in hepatic blood from cows with fastinginduced hepatic lipidosis. Can J Vet Res 74: 317-320.

8. Pullen DL, Liesman JS, Emery RS (1990) A species comparison of liver slice synthesis and secretion of triacylglycerol form nonesterified fatty acids in media. J Anim Sci 68: 1395-1399.

9. Bobe G, Ametaj BN, Young JW, Beitz DC (2003) Effects of exogenous glucagon on lipids in lipoproteins and liver of lactating dairy cows. J Dairy Sci 86: 2895-2903

10. Bobe G, Ametaj BN, Young JW, Beitz DC (2003) Potential treatment of fatty liver with 14-day subcutaneous injections of glucagon. J Dairy Sci 86: 3138 3147.

11. Starke A, Haudum A, Weijers G, Herzog K, Wohlsein P et al. (2010) Noninvasive detection of hepatic lipidosis in dairy cows with calibrated ultrasonographic image analysis. J Dairy Sci 93: 2952-2965.

12. Smith TR, Hippen AR, Beitz DC, Young JW (1997) Metabolic characteristics of induced ketosis in normal and obese dairy cows. J Dairy Sci 80: 1569-1581.

13. Theodossi A, Spiegelhalter D, Portmann B, Eddleston AL, Williams R (1983) The value of clinical, biochemical, ultrasound and liver biopsy data in assessing patients with liver disease. Liver. 3: 315-326.

14. Braun U (2009) Ultrasonography of the liver in cattle. Vet Clin North Am Food Anim Pract 25: 591-609.

15. Biller DS, Kantrowitz B, Miyabayashi T (1992) Ultrasonography of diffuse liver disease. A review. J Vet Intern Med 6: 71-76.

16. Acorda JA, Yamada H, Ghamsari SM (1995) Comparative evaluation of fatty infiltration of the liver in dairy cattle by using blood and serum analysis, ultrasonography, and digital analysis. Vet Q. 17: 12-14

17. Acorda JA, Yamada H, Ghamsari, SM (1994) Evaluation of fatty infiltration of the liver in dairy cattle through digital analysis of hepatic ultrasonograms. Veterinary Radiology \& Ultrasound 35: 120-123.

18. Bobe G, Amin VR, Hippen AR, She P, Young JW et al. (2008) Noninvasive detection of fatty liver in dairy cows by digital analyses of hepatic ultrasonograms. J Dairy Res 75: 84-89.

19. Edmonson AJ, Lean IJ, Weaver LD, Farver F, Webster G (1989) A Body Condition Scoring Chart for Holstein Dairy Cows. Journal of Dairy Science 72 68-78

20. Radostits OM, Mayhew IG, Houston DM (2000) Veterinary Clinical Examination and Diagnosis. W.B. Saunders, London.

21. Mohamed T, Oikawa S, Iwasaki Y, Mizunuma Y, Takehana K et al. (2004) Metabolic profiles and bile acid extraction rate in the liver of cows with fasting induced hepatic lipidosis. J Vet Med A Physiol Pathol Clin Med 51: 113-118.

22. Mohamed T, Oikawa S, Kurosawa T, Hosaka Y, Takehana K et al. (2004) Focal fatty liver in a heifer: utility of ultrasonography in diagnosis. J Vet Med Sci 66 : 341-344 
Citation: Tharwat M, Oikawa S, Buczinski S (2012) Ultrasonographic Prediction of Hepatic Fat Content in Dairy Cows during the Transition Period. J Veterinar Sci Technol 3:111. doi:10.4172/2157-7579.1000111

Page 5 of 5

23. Mohamed T, Sato H, Kurosawa T, Oikawa S (2002) Echo-guided studies on portal and hepatic blood in cattle. J Vet Med Sci 64: 23-28.

24. Mohamed T, Sato H, Kurosawa T, Oikawa S, Nitanai A (2003) Ultrasonographic imaging of experimentally induced pancreatitis in cattle. Vet J 165: 314-324.

25. Mohamed T, Oikawa S (2008) Efficacy and safety of ultrasound-guided percutaneous biopsy of the right kidney in cattle. J Vet Med Sci 70: 175-179.

26. SPSS (2007) Statistical Package for Social Sciences, SPSS Inc., Chicago, IL, USA Copyright $\odot$ for Windows, version 16.0.

27. Drackley JK, Overton TR, Douglas GN (2001) Adaptations of Glucose and LongChain Fatty Acid Metabolism in Liver of Dairy Cows During the Periparturient Period. J Dairy Sci 84 (E. Suppl.): E100-E112

28. Jorritsma R, Jorritsma H, Schukken YH, Bartlett PC, Wensing T et al. (2000) Prevalence and indicators of post partum fatty infiltration of the liver in nine commercial dairy herds in The Netherlands. Livestock Production Science 68: $53-60$.
29. Van den Top AM, Wensing T, Geelen MJ, Wentink GH, van't Klooster AT et al. (1996) Higher postpartum hepatic triacylglycerol concentrations in dairy cows with free rather than restricted access to feed during the dry period are associated with lower activities of hepatic glycerolphosphate acyltransferase. $J$ Nutr 126: 76-85

30. Behan M, Kazam, E (1978) The echographic characteristics of fatty tissues and tumors. Radiology 129: 143-151.

31. Sanders, RC, James, EA (1980) The principles and practice of ultrasonography in obstetrics and gynecology. $2^{\text {nd }} \mathrm{ed}$, New York. Appleton-Century-Croft.

32. Joseph AE, Dewbury KC, McGuire PG (1979) Ultrasound in the detection of chronic liver disease (the "bright liver"). Br J Radiol 52: 184-188.

33. Strauss S, Gavish E, Gottlieb P, Katsnelson L (2007) Interobserver and intraobserver variability in the sonographic assessment of fatty liver. AJR Am J Roentgenol 189: W320-W323. 